\title{
Severe viral oesophagitis, pharyngitis, and stomatitis as antecedents of ileocecal Crohn's disease
}

\author{
Grzegorz Boryczka ${ }^{1}$, Marek Waluga ${ }^{1}$, Agnieszka Budzyńska ${ }^{1}$, Maciej Kajor ${ }^{2}$, Marek Hartleb $^{1}$ \\ ${ }^{1}$ Department of Gastroenterology and Hepatology, Medical University of Silesia, Katowice, Poland \\ ${ }^{2}$ Department of Pathomorphology, Medical University of Silesia, Katowice, Poland
}

Prz Gastroenterol 2015; 10 (1): 47-50

DOI: $10.5114 / p g .2014 .47495$

Key words: viral oesophagitis, erosive oesophagitis, Crohn's disease.

Address for correspondence: Grzegorz Boryczka MD, PhD, Department of Gastroenterology and Hepatology, Medical University of Silesia, 14 Medykow St, 40-752 Katowice, Poland, phone: +48 3278944 01, fax: +32 78944 02, e-mail: grzegorzboryczka@op.pl

\begin{abstract}
We present a 22-year-old male who developed a severe erosive oesophagitis extending to the pharynx and oral cavity without obvious risk factors. Endoscopic image suggested viral aetiology that could not be confirmed by routine serological diagnostics of infections with cytomegalovirus, Epstein-Barr virus, and Herpes simplex virus. The histopathological evaluation also gave no definite clues to the aetiology of the inflammation. Treatment with acyclovir was ineffective, but gancyclovir therapy caused spectacular clinical improvement and healing of erosions. Two months later the patient presented febrile diarrhoea that was a symptom of ileocecal Crohn's disease proven by endoscopy, enterography, and histopathology. It is the first report of severe viral oesophagitis preceding clinical manifestation of Crohn's disease. This observation warrants further study towards the viral aetiology of oral, pharyngeal, and oesophageal erosions, frequently associated with Crohn's disease.
\end{abstract}

\section{Introduction}

Oesophagitis may be induced by a wide spectrum of local or systemic factors. The most common cause of oesophagitis is gastroesophageal reflux disease, the frequency of which in the general population is estimated at approximately 5\% [1]. Other aetiological factors of oesophagus inflammation include drugs (e.g. aspirin, ascorbic acid, doxycycline, potassium salts), infections by viruses, fungi, bacteria or protozoa (e.g. actinomycosis, nocardiosis, tuberculosis, syphilis, Chagas disease), X-rays, autoimmune diseases (e.g. Crohn's disease, Behçet disease, pemphigus, graft versus host disease after bone marrow transplant), and chemical injury after involuntary consumption of acids or alkalis [2, 3]. Clinical symptoms of oesophagitis are independent of the aetiology and most often include retrosternal burning, odynophagia, dysphagia, epigastric pain, sitofobia, fagofobia, or fever and influenza-like illness. The initial clinical presentation of esophagitis may also come from its complications such as gastrointestinal bleeding, oesophageal stricture, perforation, or fistula to neighbouring organs [2, 4-7].

Here, we present a case of a young man suffering from severe viral oesophagitis, who developed Crohn's disease several months later.

\section{Case report}

A 22-year-old student was admitted to our department because of intense sore throat, disturbances of solid food swallowing, epigastric pain, and high fever up to $40^{\circ} \mathrm{C}$ lasting for 2 days. Four months earlier the patient was hospitalised because of similar symptoms in the laryngological ward, where erosive inflammation of the oral cavity and throat was diagnosed. Infections with Epstein-Barr virus (EBV), Cytomegalovirus (CMV), and HIV were serologically excluded. Blood cultures were negative on three repeated examinations, but Streptoccocus pyogenes was cultured from the throat and Candida albicans from oral cavity smear. Acyclovir and fluconazole were used with satisfactory clinical effect.

On the day of admission to our department the patient was conscious with logical verbal contact. He complained of lack of appetite, salivation, significant weakness, and weight loss of about $5 \mathrm{~kg}$ during 4 months. Body mass index (BMI) was $22 \mathrm{~kg} / \mathrm{m}^{2}$. The patient did not suffer from chronic diseases. On examination large numbers of erosions localised in the vermillion and the mucosa of the oral cavity and throat were found. His body temperature was $39^{\circ} \mathrm{C}$. Abnormal laboratory data included: leucocytosis of $11300 / \mathrm{mm}^{3}$ 
with the increased percentage of neutrophils to $74.1 \%$ and monocytes to $13.9 \%$, and reduced percentage of lymphocytes (to $11.6 \%$ ). The concentration of C-reactive protein (CRP) was $102.6 \mathrm{mg} / \mathrm{l}$ (normal range $<5 \mathrm{mg} / \mathrm{l}$ ). Other laboratory tests were normal and bacterial blood culture was negative. Endoscopy revealed swelling of the epiglottis with numerous aphthae visible on the larynx folds (Figure 1). In the oesophagus, starting from $28 \mathrm{~cm}$ from the incisor teeth to the cardia, the whole mucosal surface was covered with innumerable erosions of various shapes and merging tendency. Over the cardia, erosions occupied almost $100 \%$ of the oesophagus surface (Figure 2). They were covered with white fibrin, and some with tiny blood clots. There was no patchy white exudate typical for fungal infection. The line $Z$ was placed at the correct height and the cardia was opened wide. Tissue samples were taken for histopathology from the lower segment of the oesophagus. In addition, a single linear erosion of several millimetres was found in the prepyloric part of the stomach, as well as several aphthae in the duodenal bulb. In the histopathological examination of the oesophageal samples, extensive necrosis and massive infiltration of granulocytes with threads of mycelium was found.

Considering endoscopy and previous positive response to acyclovir, viral esophagitis was diagnosed. Fragments of the mycelium were treated as superinfection. Oral feeding was stopped and oral acyclovir $5 \times 200 \mathrm{mg}$, antibiotic cover $(2 \times 1 \mathrm{~g}$ i.v. ceftriaxone), oral fluconazole $2 \times 100 \mathrm{mg}$, probiotics, and pantoprazole $(2 \times 40 \mathrm{mg}$ i.v. $)$ were used. Brushing the mouth with nystatin and gentian, and rinsing the hydrogen peroxide solution several times a day were also applied. There was no clinical

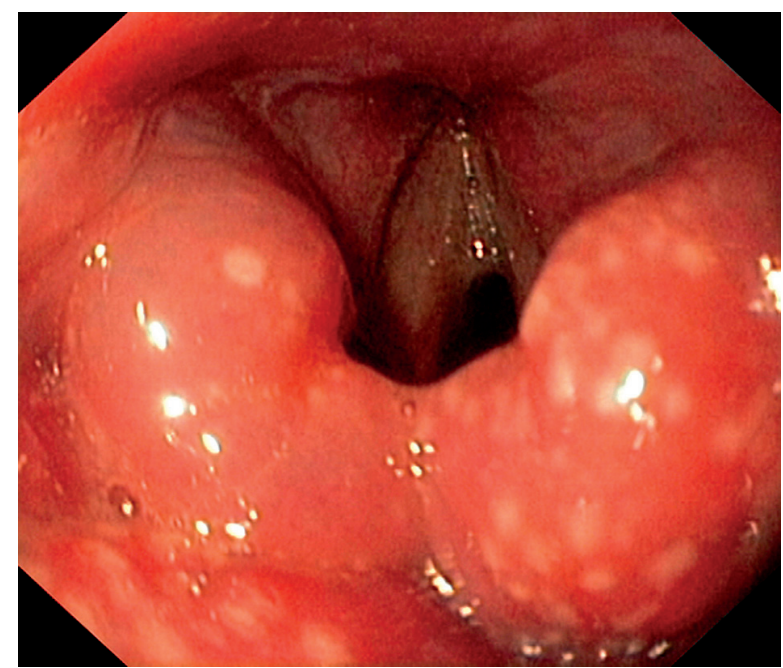

Figure 1. Oedema of the epiglottis with numerous aphthae improvement with this treatment; the fever persisted and the concentration of C-reactive protein (CRP) on the sixth day of hospitalisation was $174.9 \mathrm{mg} / \mathrm{l}$ and leucocytosis increased to $12100 / \mathrm{mm}^{3}$. Active infections of HIV, CMV, EBV, and Herpes simplex virus (HSV) were serologically excluded; however, anti-CMV and anti-EBV antibodies were found within $\mathrm{G}$ class immunoglobulin. We decided to change acyclovir to ganciclovir, which was given for 21 days at a dose of $2 \times 300 \mathrm{mg}$ i.v. After several days this treatment swift clinical improvement was seen, with disappearance of all symptoms, including sore throat, dysphagia, abdominal pain, and fever. Vermillion and throat erosions healed. On the following days appetite returned to normal and serum CRP level and leucocytosis normalised. Endoscopy performed 4 weeks after initiation of ganciclovir showed complete healing of oesophageal erosions. The patient was discharged on the $34^{\text {th }}$ day with the recommendation that he make laboratory tests specific for immunodeficiency.

Two months later the patient developed diarrhoea and subfebrile state, associated with an elevated serum level of CRP (36 mg/l), and normal leucocytes count. Bacteriological examination excluded the presence of pathological microorganisms in faeces. The patient was admitted to the Department of Allergy and Immunology of the University Hospital in Krakow, where hormonal and cellular immune deficiencies were excluded, and the presence of IgA and IgG anti-Saccharomyces cerevisiae (ASCA) was found.

Four months later the patient was re-admitted to our department to find the cause of loose stools containing small amounts of mucus and blood with bowel movements not exceeding three a day. The patient

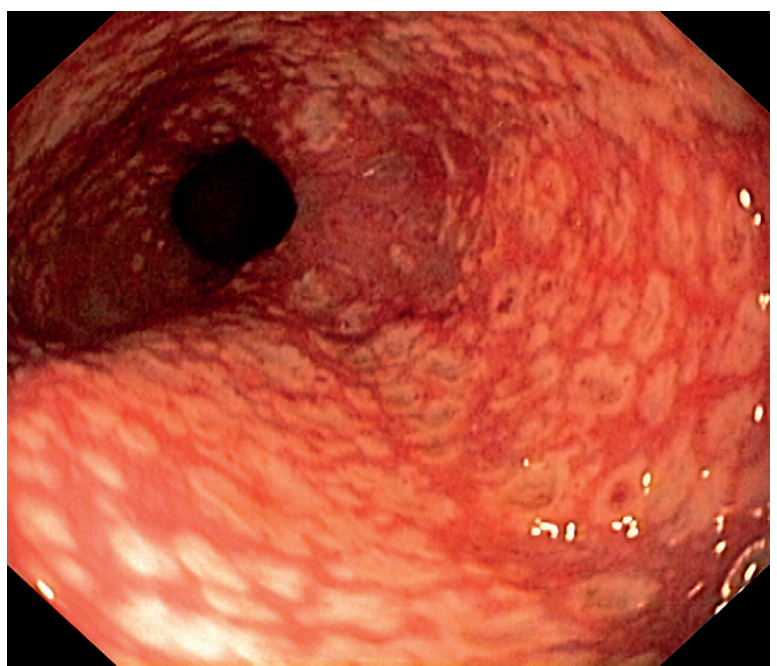

Figure 2. Erosions in the lower part of the oesophagus 
complained of abdominal pain occurring during defecation. Since the previous hospitalisation there was an increase in body weight of $7 \mathrm{~kg}\left(\mathrm{BMI} 24.7 \mathrm{~kg} / \mathrm{m}^{2}\right)$. Physical examination showed again the erosions in the mouth and throat. Basic laboratory tests were normal and viral tests for infections of HIV and hepatitis B and C were negative. Infections of Yersinia enterocolitica, Chlamydia trachomatis, and Helicobacter pylori were also excluded. Endoscopic image of the oesophagus was normal but scattered aphthae in the duodenal bulb and descending duodenum were described. In histopathology there was active chronic non-specific inflammation of the duodenum. Colonoscopy disclosed erosions in the rectum and sigmoid colon. In addition, the Bauhin's valve was swollen with a single erosion, and the terminal ileum showed a faded vascular pattern with several fine erosions. Histopathology of the mucosal samples taken from Bauhin's valve showed high-density mixed lymphocytic-granulocytic inflammatory infiltrate within the lamina propria (Figure 3). Nuclear magnetic resonance enterography ascertained thickening of the wall of the distal part of the small bowel with excessive contrast enhancement. Upon treatment with $3 \mathrm{~g}$ mesalazine and $9 \mathrm{mg}$ budesonide, loose stools and pain disappeared. The patient was discharged from hospital with a diagnosis of ileocecal Crohn's disease.

\section{Discussion}

The diagnosis of non-reflux esophagitis can be difficult. Recognition of infectious aetiology of esophagitis is mostly based on serological, immunological, and biomolecular examinations $[2,3,5]$. In the reported patient, viral aetiology of oesophagitis was concluded from the typical endoscopic image and spectacular improvement after use of ganciclovir, without confirmation by serological studies that did not include some strains of Herpes viruses. Besides, newly developed viral infection is responsible for increasing the serum level of specific immunoglobulin M class, while re-infections with HSV, CMV, or EBV cause a rise in immunoglobulin class $G$ [8]. In the reported patient the first episode of oesophagitis could be the result of a primary infection with one of these viruses, such as acyclovir, which showed striking efficacy and has significant activity against both types of HSV, varicella-zoster virus and EBV, but has a poor effect on CMV [9]. By contrast, ganciclovir has a strong inhibitory effect on the replication of CMV and shows a much weaker influence on different types of HSV, varicella-zoster virus, and EBV.

Endoscopic image of infectious esophagitis depends on the aetiological factor. HSV infection is the cause of development of mucosal bladders and raised edged small ulcers with the presence of exudate in the cen-

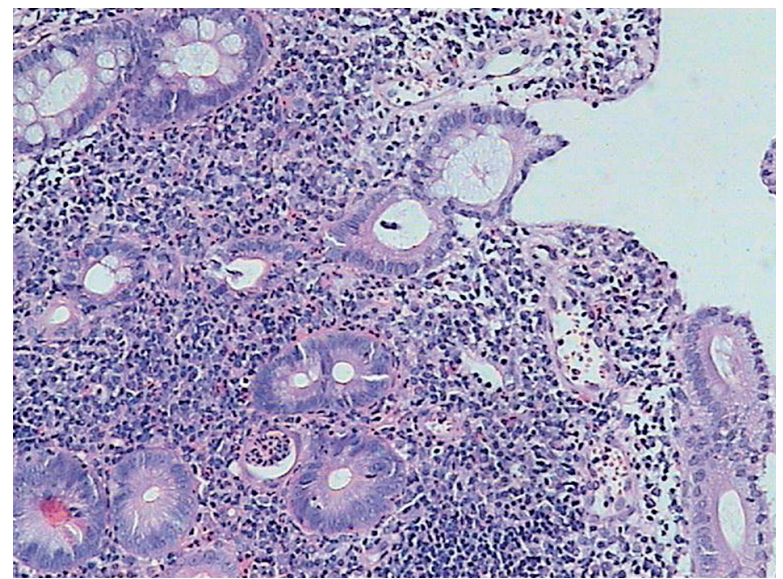

Figure 3. Inflammatory infiltration of Bauhin's valve. Magnification $100 \times, \mathrm{H}+\mathrm{E}$

tral part of the ulcer. Extensive erosions or geographical ulcers with flat edges and without exudate are characteristic for CMV infection. In turn, a yellow or cream-coloured coating on mucosal surfaces occurs in fungal infections. Bacteria and protozoans cause deep, irregular ulcers resembling cancer $[3,6,7]$. In our patient the histopathological examination disclosed no intra-nuclear inclusions typical of HSV and CMV infection $[3,6]$. However, in differential diagnostics it should be taken into account that biopsy material may be not be representative for a given disease. In HSV infection it is recommended to take samples from the edge of ulcers but from their bottoms in CMV infection. In the case of fungal and bacterial infections the site of mucosa sampling is not so important $[3,6]$.

Infectious esophagitis is usually the consequence of primary or secondary immunodeficiency occurring during HIV infection, cancer, chemotherapy, corticosteroid therapy, or immunosuppression. These conditions were ruled out in our patient. Oesophagus viral infections in patients with an intact immune system are very rare, although several cases of esophagitis caused by HSV in patients without perceptible risk factor were reported [2-6]. A propensity for oesophageal infection may result from disturbance of oesophagus motility, chronic antibiotic therapy, significant malnutrition, chronic metabolic disease (e.g. diabetes), mechanical injury of the oesophagus, and infection of surrounding tissues. Clinically severe disease, dysphagia, or ineffective peroral treatment indicates the need to use intravenous therapy (ganciclovir, foscarnet, cidofovir) lasting not less than 10 days $[2,6,10,11]$. To avoid recurrence of esophagitis the antiviral treatment in our patient was continued for 21 days.

Two months after antiviral therapy our patient noticed loose stools and febrile states. Radiological, en- 
doscopic, and histological studies allowed us to recognise ileocecal Crohn's disease. The literature reports on acute CMV infections causing ileitis, closely imitating Crohn's disease, and responding well to treatment with ganciclovir [12]. There are also cases in which intestinal CMV infection occurred simultaneously with the first symptoms of non-specific inflammatory bowel disease, greatly hindering the final diagnosis [13-15]. None of these circumstances was present in our patient. According to the registry of patients with Crohn's disease maintained on the website eHealthMe, the bowel disease wisas preceded by HSV infection in $0.6 \%$ of cases. We do not believe that a viral infection in our patient was responsible for exacerbation (because the period of latency was too long) or the development of Crohn's disease, although among the aetiological factors of Crohn's disease different microorganisms have still been considered (bacteria, protozoa, viruses).

Viral superinfections of the gastrointestinal tract with CMV and more rarely with HSV occur frequently in patients treated with high doses of immunosuppressive drugs [16]. Such cases may be mistakenly interpreted as resistance to corticosteroids or immunosuppressants. In our patient severe erosive oesophagitis occurred without concomitant use of immunosuppressive drugs. However, it is possible that Crohn's disease itself is responsible for endogenous immunosuppression favouring an atypical clinical course of viral infections. The phenomenon of immunoparesis is also known to be present in other autoimmune diseases, including severe systemic colagenosis or severe autoimmune hepatitis $[17,18]$.

In our patient ganciclovir resulted in quick healing of erosive mucosal lesions not only in the oesophagus, but also in the mouth, throat, and the duodenum, indicating that the inflammation was of viral origin. Chronic or recurrent presence of aphthae in the oral cavity is found in $5-27 \%$ of patients with Crohn's disease [19]. Furthermore, erosive inflammation of the oesophagus, stomach, or duodenum occurs in up to $43 \%$ of patients with this disease [20].

\section{Conclusions}

This case also shows that patients with Crohn's disease associated with erosive inflammation in the upper digestive tract require diagnostics for viral infections.

\section{Conflict of interest}

The authors declare no conflict of interest.

\section{References}

1. Johanson JF. Epidemiology of esophageal and supraesophageal reflux injuries. Am J Med 2000; 108: 99-103.
2. Thor PJ. Oesophagus diseases. In: Clinical gastroenterology and hepatology [Polish]. Konturek SJ (ed.). Wydawnictwo Lekarskie PZWL, Warsaw 2006; 61-2.

3. Silverstein FE, Guido NJ, Tytgat T, et al. Endoscopy of digestive tract [Polish]. Medycyna Praktyczna, Krakow 1998.

4. Riediger C, Sauer P, Matevossian E, et al. Herpes simplex virus sepsis and acute liver failure. Clin Transplant 2009; 23: 37-41.

5. Canalejo E, Duran FG, Cabello N, et al. Herpes esophagitis in healthy adults and adolescents. Report of 3 cases and review of the literature. Medicine 2010; 89: 204-10.

6. Bayless TM, Diehl AM. Gastroenterology and liver diseases [Polish]. Czelej, Lublin 2005.

7. Ginsberg GG. Clinical endoscopy of digestive tract [Polish]. Medipage, Warsaw 2009.

8. Olszyńska-Krowicka M, Kajfasz P. Infections causing by DNAviruses. In: Infectious and parasitic diseases [Polish]. Dziubek Z (ed.). Wydawnictwo Lekarskie PZWL, Warsaw 2000; 193-219.

9. Collins P. The spectrum of antiviral activities of acyclovir in vitro and in vivo. J Antimicrob Chemother 1983; 12: 19-27.

10. Winston DJ, Yeager AM, Chandrasekar PH, et al. Randomized comparison of oral valacyclowir and intravenous ganciclovir for prevention of cytomegalovirus disease after allogeneic bone marrow transplantation. Dis Clin Infect 2003; 36: 749-58.

11. Blick G, Garton T, Hopkins U et al. Successful use of cidofovir in treating AIDS-related cytomegalovirus retinitis, encephalitis, and esophagitis. J Acquir Immun Defic Syn Hum Retrovirol 1997; 15: 84-5.

12. Khan FN, Prasad V, Klein MD. Cytomegalovirus enteritis mimicking Crohn's disease in a lupus nephritis patient: a case report. World J Gastroenterol 2009; 15: 4327-30.

13. Shahani L. CMV infection complicating the diagnosis of Crohn's disease in immunocompetent patient. BMJ Case Rep 2012 May 8; 2012. pii: bcr1120115254. doi: 10.1136/bcr.11.2011.5254.

14. Subramanian V, Finlayson C, Harrison T, et al. Primary cytomegalovirus infectious colitis complicating Crohn's disease successfully treated with oral valganciclovir. J Crohns Colitis 2010; 4: 199-202.

15. Carne P, Frizelle F. Cytomegalovirus and inflammatory bowel disease. N Z Med J 2003; 116: U306.

16. Rüther U, Nunnensiek C, Müller G, et al. Herpes simplex-associated exacerbation of Crohn's disease. Successful treatment with acyclovir. Dtsch Med Wochenschr 1992; 117: 46-50.

17. Hernigou P, Daltro G, Flouzat-Lachaniette CH, et al. Septic arthritis in adults with sickle cell disease often is associated with osteomyelitis or osteonecrosis. Clin Orthop Relat Res 2010; 468: 1676-81.

18. Potts JR, Verma S. Optimizing management in autoimmune hepatitis with liver failure at initial presentation. World I Gastroenterol 2011; 17: 2070-5.

19. Ślebioda Z, Szponar E, Linke K. Comparative analysis of the oral cavity status in patients with Crohn's disease and ulcerative colitis. J Stoma 2011; 64: 212-34.

20. Latos W, Sieroń-Słotny K, Gadowska-Cicha A, et al. Leśniows$\mathrm{ki}-\mathrm{Crohn}$ disease in upper part of digestive tract at 3 persons in material composed of 3000 endoscopies. Chir Pol 2006; 8: 198-206.

Received: 25.10 .2012

Accepted: 18.11 .2012 